\title{
2736. Energy absorption characteristics of cement-soil under confining pressure based on SHPB test
}

\author{
Changhui Gao ${ }^{1}$, Qinyong Ma ${ }^{2}$ \\ ${ }^{1,2}$ School of Civil Engineering and Architecture, Anhui University of Science and Technology, \\ Huainan, 232001, P. R. China \\ ${ }^{2}$ Engineering Research Center of Underground Mine Construction, Ministry of Education, \\ Anhui University of Science and Technology, Huainan, 232001, P. R. China \\ ${ }^{1,2}$ Corresponding author \\ E-mail: ${ }^{1}$ gaoch1992@126.com, ${ }^{2}$ qymaah@126.com
}

Received 30 April 2017; received in revised form 14 July 2017; accepted 23 July 2017 DOI https://doi.org/10.21595/jve.2017.18562

Abstract. Cement-soil has been widely used for engineering application. However, no attention has been paid to the energy absorption characteristics of cement-soil under impact loading. In this paper, a series of split Hopkinson pressure bar (SHPB) tests have been conducted to explore the energy absorption characteristics of cement-soil, and the effects of confining pressure (from 0 to 2.0 MPa) and strain rate (from 130 to $172 \mathrm{~s}^{-1}$ ) on the absorbed energy and the energy absorbency rate are investigated. The results show that the energy evolution of cement-soil under confining pressure is found to be similar at different strain rate. Both the absorbed energy and the energy absorbency rate are influenced by the confining pressure. Moreover, both the absorbed energy and the energy absorbency rate increase at first and then remain stable at a certain value with the increase of confining pressure. In addition, the absorbed energy linearly increases with the incident energy increasing, and a similar tendency is found between the absorbed energy and the strain rate, yet no obvious effect on the energy absorbency rate by the strain rate. Moreover, the energy mechanism of cement-soil is explained from the perspective of failure modes of cement-soil specimen.

Keywords: cement-soil, absorbed energy, energy absorbency rate, confining pressure, strain rate, SHPB.

\section{Introduction}

The stabilization of soil with Portland cement has been successfully used for improving geotechnical performance in applications such as deep excavation, pavement base layers, slop protection and underground construction works, and so on [1-3], which presents great economic and environmental benefits. Stabilization in this way improves the strength and durability of soil, reduces noise and dust in the work environment, also, improves soil workability. Moreover, many researches have been done for the strength $[4,5]$, permeability [6, 7], erosion resistance [8, 9] of cement-soil. Those published works, however, were focused only on properties of cement-soil under static loads, no attention has been paid to the dynamic properties of cement-soil.

The study on dynamic properties of cement-soil has significant relation to the engineering applications. According to the literature [10], cement-soil is often used for rapid construction of airstrip base. When the airplane comes down to the ground at $240 \mathrm{~km} / \mathrm{h}$, a strong impact will be produced on cement-soil base. In addition, present foundation treated by cement-soil, adjacent to mechanical excavation or blasting construction, always involves cement-soil responses to impact loading. Of course, earthquake loading is subjected to construction made of cement-soil now and then. Besides, dynamic load is impacted on the foundation cement-soil, in essence, which is the embodiment of dynamic property of cement-soil under confining pressure. Thus, understanding the dynamic behavior of cement-soil under confining pressure is significant to dynamic analysis and design of foundation.

According to the laws of thermodynamics, energy conversion is the basis rule of physical processes of materials. For many materials such as rock [11, 12], concrete $[13,14]$, porous materials $[15,16]$, and other materials [17-19], the essence of their damage and failure is the 
germination, extension, aggregation and connection of internal micro-cracks result in the deformation and failure under the driving of energy [20]. Energy plays an important role in deformation and failure of materials. Therefore, research of the energy absorption characteristics of cement-soil under impact loading is of great significance to evaluate the mechanism of energy evolution and anti-impact ability, which is of certain theoretical significance and practical value.

In this paper, a series of SHPB tests are carried out to investigate the energy absorption characteristics of the cement-soil under five kinds of confining pressures $(0,0.5,1.0,1.5$ and 2.0 $\mathrm{MPa}$ ), and the impact pressures are from 3.0 to 4.5 $\mathrm{MPa}$ (corresponding to different strain rates). The effect of confining pressure and strain rate on the energy absorption characteristics of the cement-soil, including the absorbed energy, the incident energy, and the energy absorbency rate, are evaluated in this work.

\section{Experimental program and energy calculation}

\subsection{Effectiveness analysis of test data}

The $\varnothing 50 \mathrm{~mm}$ split Hopkinson pressure bar (SHPB) apparatus is adopted in the present work, and due to relatively low wave impedance of cement-soil, the semiconductor strain gauge is pasted on the transmitted bar to record the weak signal of transmitted wave. Confining pressure device is shown in Fig. 1.

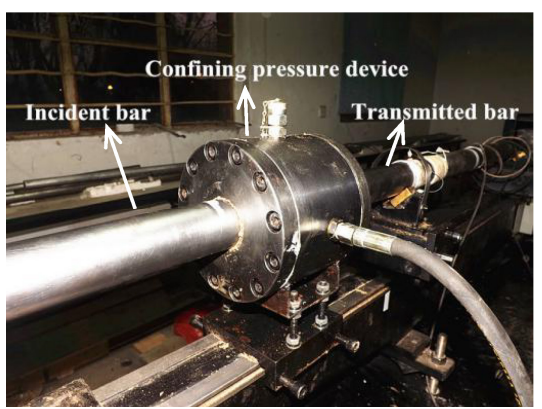

Fig. 1. Confining pressure device

In order to clarify the effectiveness of test data, the propagation theory of one-dimensional wave and uniform stress hypothesis need to be satisfied. To solve the problem of uniform stress in SHPB tests, some measures were taken and original waveform collected in SHPB test is shown in Fig. 2. As clear in Fig. 2, the half-sine wave pattern loading is achieved and the waveform is smooth. It also can be found that the time of the rising edge of incident pulse is about $0.14 \mathrm{~ms}$, and the time of duration is about $0.4 \mathrm{~ms}$. So, the number of transmission-reflection cycles $\left(c_{t-f}\right)$ for stress pulse in cement-soil specimen can be calculated by the following Eq. (1) as:

$c_{t-f}=\frac{t_{r}}{t_{t-f}}$

where $t_{r}$ is the time of the rising edge of incident pulse (about $0.14 \mathrm{~ms}$ ), $t_{t-f}$ is the time of one transmission-reflection cycle for stress pulse in cement-soil specimen.

And, $t_{t-f}$ can be expressed as:

$t_{t-f}=\frac{2 h}{v}$

where $h$ is the length of specimen $(0.025 \mathrm{~m}), v$ is the propagation velocity of stress pulse in 
cement-soil (about $1450 \mathrm{~m} / \mathrm{s}$ ), so the $t_{t-f}$ is $0.0345 \mathrm{~ms}$.

Finally, $c_{t-f}$ can be obtained by calculation as:

$c_{t-f}=\frac{0.14}{0.0345}>4$

Thus, there is enough time to achieve uniform stress state for cement-soil specimen.

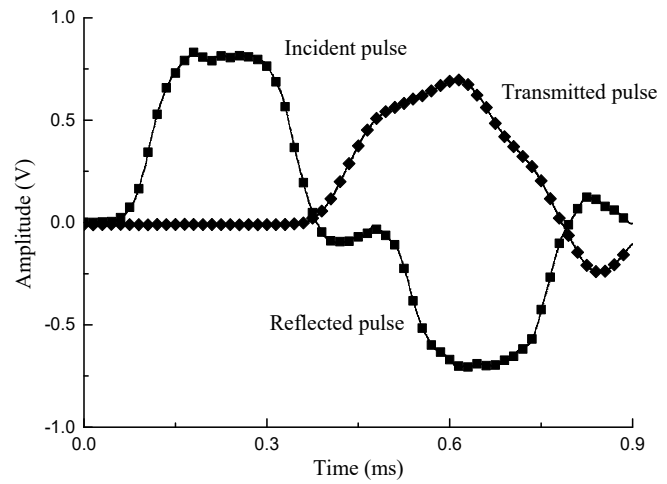

Fig. 2. Original waveform $\left(C_{p}=2.0 \mathrm{MPa}, I_{p}=0.3 \mathrm{MPa}\right) . C_{p}$ - confining pressure; $I_{p}$ - impact loading pressure (below)

The theory of one-dimensional wave requires $\lambda=c t>5 d[21]$, where $\lambda$ is the width of incident stress pules, $c$ is P-wave velocity $(5190 \mathrm{~m} / \mathrm{s}), t$ is the propagation time of stress pulse $(0.04 \mathrm{~ms}), d$ is the diameter of specimen $(0.05 \mathrm{~m})$. It can be obtained by calculation as:

$\lambda=2.076>5 d=0.25$.

Therefore, the theory of one-dimensional wave can be clarified.

\subsection{Materials}

The silty clay tested in this investigation was obtained from foundation and its physical properties and grain size distribution are shown in Table 1 and Table 2, respectively. Ordinary Portland cement (P.O 42.5) was used as the binding agent in this work. Distilled water was used for specimen preparation.

Table 1. Basic physical properties of silty clay

\begin{tabular}{|c|c|c|c|c|}
\hline $\begin{array}{c}\text { Liquid limit } \\
(\%)\end{array}$ & $\begin{array}{c}\text { Plasticity limit } \\
(\%)\end{array}$ & $\begin{array}{c}\text { Plasticity } \\
\text { index }\end{array}$ & $\begin{array}{c}\text { Optimum moisture } \\
\text { content }(\%)\end{array}$ & $\begin{array}{c}\text { Maximum dry density } \\
\left(\mathrm{g} \cdot \mathrm{cm}^{-3}\right)\end{array}$ \\
\hline 35.40 & 23.82 & 11.58 & 22.40 & 1.69 \\
\hline
\end{tabular}

Table 2. The grain size distribution of silty clay

\begin{tabular}{|c|c|c|c|}
\hline Grain size $(\mathrm{mm})$ & Content $(\%)$ & Grain size $(\mathrm{mm})$ & Content $(\%)$ \\
\hline$d \leq 0.005$ & 19.54 & $0.005<d \leq 0.075$ & 40.23 \\
\hline $0.075<d \leq 0.25$ & 12.70 & $0.25<d \leq 0.5$ & 16.05 \\
\hline $0.5<d \leq 1$ & 9.08 & $1<d \leq 2$ & 2.40 \\
\hline
\end{tabular}

\subsection{Methods of energy calculation}

Absorbed energy $\left(W_{S}\right)$, which is the capacity to absorb energy of stress wave for cement-soil per unit volume, can be expressed as follow: 
$W_{S}=W_{I}-W_{R}-W_{T}$,

where $W_{I}, W_{R}$ and $W_{T}$ are the energy of incident wave, reflected wave and transmitted wave, respectively, they can be calculated through Eq. (6):

$W_{i}=E C A \int_{0}^{\tau} \varepsilon_{i}^{2}(t) d t, \quad i=I, R, T$,

where $E, C$, and $A$ are the Young's modulus, P-wave velocity and the cross-sectional area, respectively; $\varepsilon_{I}(t), \varepsilon_{R}(t)$ and $\varepsilon_{T}(t)$ are the strain of incident wave, reflected wave, and transmitted wave, respectively; $t$ is the duration time of elastic wave.

\section{Results and discussion}

\subsection{Relationship between the absorbed energy and the incident energy}

Through Eq. (5) and (6), the representative energy-time curve of cement-soil is obtained and shown in Fig. 3. In the initial loading, the incident energy increase rapidly with the propagation of stress wave, but the absorbed energy of cement-soil has a slight increase with the extension of stress wave. That is because most of incident energy is reflected back into incident bar, some is absorbed by cement-soil specimen, and only a small percentage of incident energy is transferred to transmitted bar [22]. It also can be seen that the time duration of the stress wave is about $0.35 \mathrm{~ms}$, and the values of incident energy and absorbed energy maintain stable after reaching a certain time about $0.275 \mathrm{~ms}$, which means the failure of cement-soil specimen.

Fig. 4 shows the relationship between the incident energy and the absorbed energy of cementsoil in SHPB test. From Fig. 4, the absorbed energy of cement-soil under different confining pressure increase with the increase of incident energy, and there is a good liner relationship between the incident energy and absorbed energy, which can be expressed as Eq. (7):

$W_{S}=a+b \cdot W_{I}$,

where $W_{s}$ and $W_{I}$ are the absorbed energy and incident energy, respectively; $a$ and $b$ are the parameters of fitting equation. The values of $a, b$ and $R^{2}$ are listed in Table 3 (for the range of incident energy is from 50 to $120 \mathrm{~J}$ ).

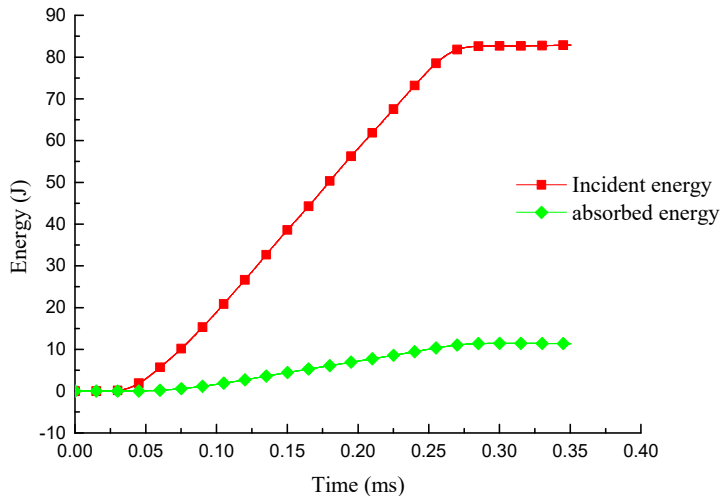

Fig. 3. Energy-time curve of the cement-soil $\left(C_{p}=2.0 \mathrm{MPa}, I_{p}=0.3 \mathrm{MPa}\right)$

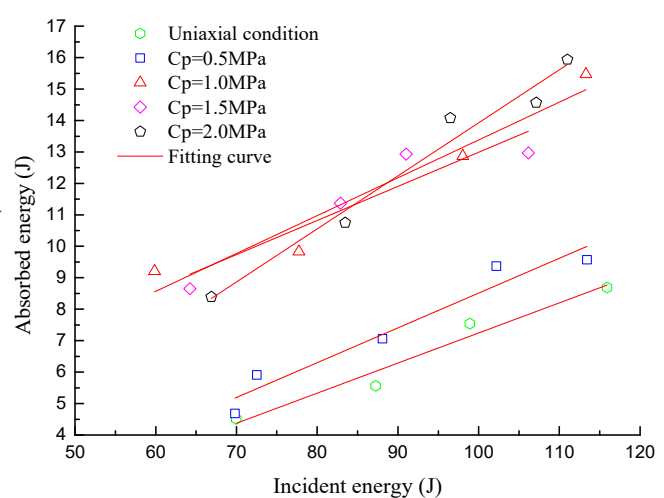

Fig. 4. Relationship between the incident energy and the absorbed energy 


\subsection{Absorbed energy of cement-soil}

The absorbed energy under different confining pressure have been calculated and the relationship between the absorbed energy and confining pressure is shown in Fig. 5. It can be observed that absorbed energy is sensitive to the value of confining pressure, and the relationship between absorbed energy and confining pressure is also influenced by the change of strain rate.

Table 3. Values of $a, b$ and correlation coefficient $R^{2}$

\begin{tabular}{|c|c|c|c|}
\hline Confining pressure (MPa) & $a$ & $b$ & $R^{2}$ \\
\hline 0 & -2.33 & 0.10 & 0.94 \\
\hline 0.5 & -2.55 & 0.11 & 0.93 \\
\hline 1.0 & 1.35 & 0.12 & 0.91 \\
\hline 1.5 & 2.14 & 0.11 & 0.81 \\
\hline 2.0 & -2.94 & 0.16 & 0.96 \\
\hline
\end{tabular}

As clear in Fig. 5, the absorbed energy increases firstly and then remains stable at a certain value with the increase of the confining pressure, which the turning point is $1.0 \mathrm{MPa}$ of the confining pressure. For example, at the strain rate of $152 \mathrm{~s}^{-1}$, the absorbed energy increase from 4.51 to $9.83 \mathrm{~J}$ with the confining pressures increasing from 0 to $1.0 \mathrm{MPa}$, after that, there is a relatively steady trend for the value of absorbed energy when the confining pressure is more than 1.0 MPa. In addition, the cement-soil specimens have fairly great improvement in the value of absorbed energy under confining pressure compared with that of uniaxial condition $\left(C_{p}=0 \mathrm{MPa}\right)$. It can be observed that the absorbed energy increase from 5.56 to $12.87 \mathrm{~J}$ with the confining pressures increasing from 0 to $1.0 \mathrm{MPa}$ at strain rate of $160 \mathrm{~s}^{-1}$, which causes an increase of $131.47 \%$.

The scatter diagram between absorbed energy and strain rate is shown in Fig. 6. All of groups show a similar trend that with the increase of strain rate, absorbed energy of cement-soil specimen increases. After data fitting, the relationship between the absorbed energy and strain rate can be assumed to be liner, and which can be expressed as Eq. (8):

$W_{S}=\alpha+\beta \cdot \dot{\varepsilon}$,

where $W_{s}$ is the absorbed energy of cement-soil specimen, $\alpha$ and $\beta$ are the parameters of fitting equation. The values of $\alpha, \beta$ and $R^{2}$ are listed in Table 4 (for the range of strain rate is from 130 to $\left.180 \mathrm{~s}^{-1}\right)$. Most of the values of $R^{2}$ of fitting curves are more than 0.90 , that is to say, Eq. (8) can well be described the strain rate sensitivity of the absorbed energy of cement-soil.

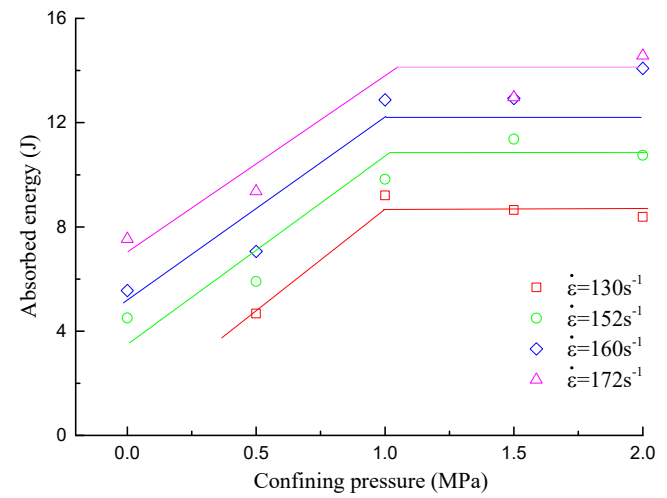

Fig. 5. Absorbed energy versus confining pressure

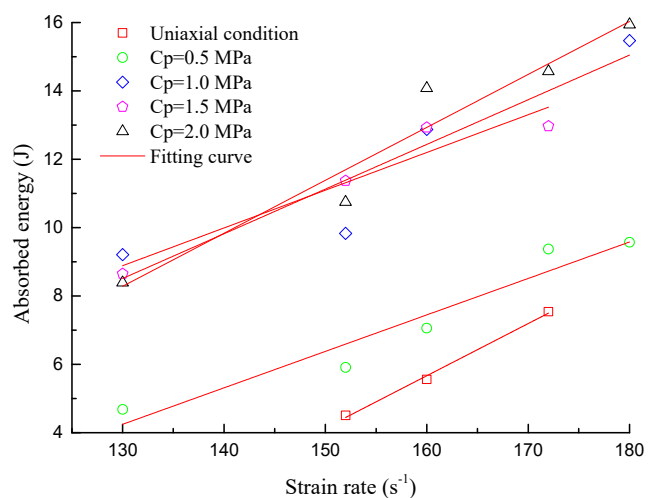

Fig. 6. Absorbed energy versus strain rate 
Table 4. Values of $\alpha, \beta$ and correlation coefficient $R^{2}$

\begin{tabular}{|c|c|c|c|}
\hline Confining pressure (MPa) & $\alpha$ & $\beta$ & $R^{2}$ \\
\hline 0 & -18.74 & 0.15 & 0.99 \\
\hline 0.5 & -9.62 & 0.11 & 0.91 \\
\hline 1.0 & -8.48 & 0.13 & 0.80 \\
\hline 1.5 & -5.47 & 0.11 & 0.89 \\
\hline 2.0 & -11.85 & 0.15 & 0.92 \\
\hline
\end{tabular}

\subsection{Energy absorbency rate of cement-soil}

In order to measure the absorption efficiency of cement-soil under confining pressure, the energy absorbency rate $\eta$ can be defined by Eq. (9):

$\eta=\frac{W_{S}}{W_{I}} \times 100 \%$,

where $W_{S}$ and $W_{I}$ are the absorbed energy and the incident energy, respectively.

Fig. 7 shows the comparison of the energy absorbency rate of cement-soil with different confining pressure and strain rate. It is can be seen that the confining pressure has an effect on the average value of energy absorbency rate. From Fig. 7(a), compared with uniaxial condition, the energy absorbency rate of cement-soil specimen has a significantly increase under confining pressure, but it shows no remarkable change when the value of confining pressure is from 1.0 to 2.0 MPa, which settles around a range of values about $12.0 \%-14.0 \%$. By examining Fig. 7(b), there is no obvious regularity between the energy absorbency rate and strain rate.

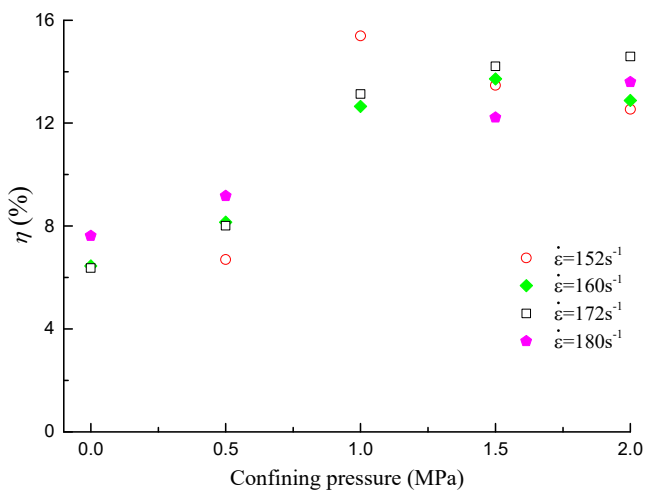

a)

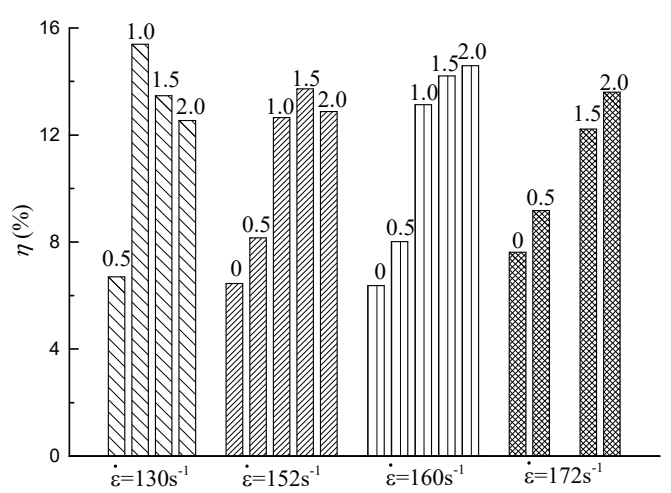

b)

Fig. 7. Relationship among the confining pressure, strain rate and the energy absorbency rate

\subsection{Discussion of energy mechanism for cement-soil}

Test results both in this paper and of other studies [23-25] conclude that both the absorbed energy and the energy absorbency rate of the materials are influenced by the confining pressure. As for cement-soil tested in this work, its absorbed energy increases firstly and then decreases with the increase of the value of confining pressure, and so does the energy absorbency rate. The effect mechanism of confining pressure on energy absorption characteristics of cement-soil can be expressed as follow:

The critical state confining pressure, which is varies for different kinds of material, has been proposed in the previous literatures $[26,27]$. There has a difference in the state of low confining pressure and high confining pressure for rock and soil as well as cement-soil. Specifically, both the absorbed energy and the energy absorbency rate of cement-soil increase with the increase of confining pressure when the values of confining pressure is lower than the critical state confining 
pressure, while the confining pressure show a negative effect on energy absorption when it is over the critical state confining pressure. In this paper, for cement-soil under confining pressure, a value of critical state confining pressure, about $1.0 \mathrm{MPa}$, is founded. Both the absorbed energy and the energy absorbency rate increase with the increase of confining pressure from 0 to $1.0 \mathrm{MPa}$, and then remain stable at a certain value with further increase of confining pressure. Such a similar result was presented by Jin [28]. Analyzing the causes, the counterforce during the lateral deformation of specimen under impact load increases with the value of confining pressure increasing, and then it is difficult for cracks inside of specimen to extend so that the absorbed energy of specimen keeps steady gradually [29]. On a macro level, the result of this behavior shows a smaller energy absorbency rate for cement-soil.

Compared with the uniaxial condition, the values of absorbed energy and the energy absorbency rate of cement-soil under confining pressure have a significant increase. Due to the energy absorption characteristics are closely related to the failure mode of specimen, so it can be explained through Fig. 8 and Fig. 9 that show the failure modes of cement-soil under different stress state. The cement-soil specimen under uniaxial state is broken into fragments, however, a better integrity for specimen is maintained under confining pressure state. Previous research showed that the initiation and propagation of fracture crack and deformation of specimen are limited under confining pressure state [30], so if the cement-soil specimen want to reach its failure state, more energy should be absorbed. That is to say, the confining pressure strengthens the capacity of energy absorption for cement-soil [31]. Thus, the absorbed energy and the energy absorbency rate increase naturally.

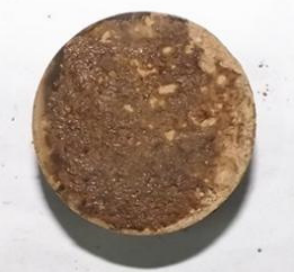

a) $C_{p}=0.5 \mathrm{MPa}$, strain rate $130 \mathrm{~s}^{-1}$

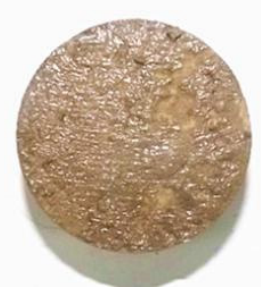

b) $C_{p}=1.5 \mathrm{MPa}$, strain rate $152 \mathrm{~s}^{-1}$

Fig. 8. Failure modes of cement-soil under confining pressure

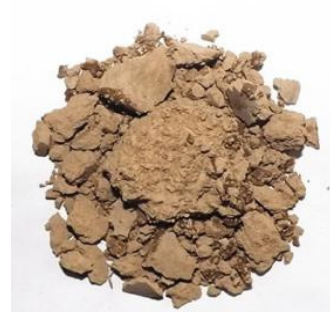

a) strain rate $152 \mathrm{~s}^{-1}$

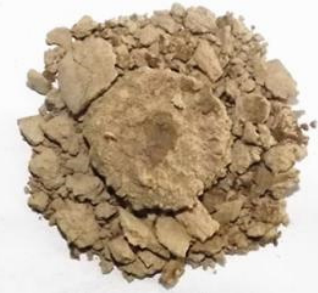

b) strain rate $160 \mathrm{~s}^{-1}$

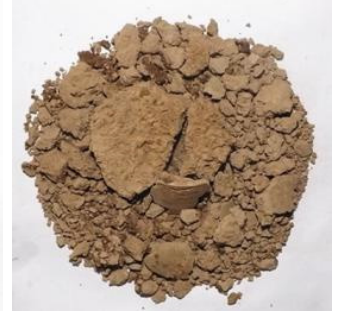

c) strain rate $172 \mathrm{~s}^{-1}$

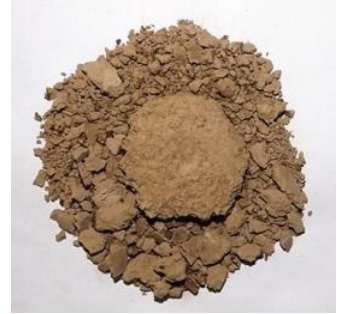

d) strain rate $180 \mathrm{~s}^{-1}$

Fig. 9. Failure modes of cement-soil under uniaxial condition

Many researches $[17,32]$ including this work show that the absorbed energy of cement-soil specimen is also related to the strain rate. In other words, the higher the strain rate, the more energy is absorbed for specimen. The strain rate effect on the absorbed energy of cement-soil is simply summarized in this paper.

In general, the value of strain rate has a positive correlation with impact loading pressure, so the higher the strain rate, the higher the impact loading pressure, which also means that incident energy increases gradually. Combining with the analysis in Section 3.1 and it can be found that the more energy is absorbed by cement-soil specimen with the increase of incident energy.

Mechanism of the strain rate effects on the energy absorption of cement-soil can also be 
explained through the failure modes of cement-soil specimen. As shown in Fig. 9, with the increasing of strain rate, the grain size of fragments becomes smaller and the number of fragments increases, which means the higher the damage degree of cement-soil specimen. From the perspective of micro-cracks and energy absorption of materials [33], the expansion of internal micro-crack and the generation of new fracture surface of cement-soil is a process of absorbing energy for cement-soil. The more serious the damage degree of cement-soil specimen is, the more energy of specimen is absorbed.

\section{Conclusions}

The energy absorption characteristics of cement-soil under confining pressure were studied for the first time. Based on SHPB test, the effects of confining pressure (from 0 to $2.0 \mathrm{MPa}$ ) and strain rate (from 130 to $172 \mathrm{~s}^{-1}$ ) on the absorbed energy and the energy absorbency rate are investigated. The absorbed energy and the energy absorbency rate of cement-soil are shown to be significantly affected by the value of confining pressure. Both the absorbed energy and the energy absorbency rate increase at first and then remain stable at a certain value with the increase of the value of confining pressure. The maximum value of the absorbed energy and the energy absorbency rate appear on the confining pressure of 1.0 MPa. The absorbed energy of cement-soil is sensitive to the strain rate, but the relationship between the energy absorbency rate and strain rate is not obvious. The more energy of cement-soil specimen is absorbed, the more serious the damage degree of specimen is. In addition, the values of absorbed energy and the energy absorbency rate of cement-soil under confining pressure have a significant increase compared with the uniaxial condition. There is a liner relationship between the absorbed energy and incident energy for cement-soil, and a similar tendency is also found between the absorbed energy and the strain rate.

\section{Acknowledgements}

Thanks to the Engineering Research Center of Underground Mine Construction, Ministry of Education and the Anhui University of Science and Technology, for providing the experiment conditions.

\section{References}

[1] Jamshidi R. J., Lake C. B., Gunning P., et al. Effect of freeze/thaw cycles on the performance and microstructure of cement-treated soils. Journal of Materials in Civil Engineering, Vol. 28, Issue 12, 2016, https://doi.org/10.1061/(ASCE)MT.1943-5533.0001677.

[2] Xiao H., Lee F. H., Liu Y. Bounding surface cam-clay model with cohesion for cement-admixed clay. International Journal of Geomechanics, Vol. 17, Issue 1, 2017, https://doi.org/10.1061/(ASCE)GM.1943-5622.0000671.

[3] Ates A. Mechanical properties of sandy soils reinforced with cement and randomly distributed glass fibers (GRC). Composites Part B Engineering, Vol. 96, 2016, p. 295-304.

[4] Consoli N. C., Zortéa F., Souza M. D., et al. Studies on the dosage of fiber-reinforced cemented soils. Journal of Materials in Civil Engineering, Vol. 23, Issue 12, 2011, p. 1624-1632.

[5] Li J. J., Liang R. W. Research on compression strength and modulus of deformation of cemented soil. Rock and Soil Mechanics, Vol. 30, Issue 2, 2009, p. 473-477.

[6] Jamshidi R. J., Lake C. B., Barnes C. L. Examining freeze/thaw cycling and its impact on the hydraulic performance of cement-treated silty sand. Journal of Cold Regions Engineering, Vol. 29, Issue 3, 2015, https://doi.org/10.1061/(ASCE)CR.1943-5495.0000081.

[7] Chen S. L., Dong K. H., Ning B. K., et al. Experiment study of penetrative behaviors on cement mixed soil. Journal of Basic Science and Engineering, Vol. 24, Issue 4, 2016, p. 759-765.

[8] Fu X. Q., Feng J. D., Xie Y. J. Mechanical behavior of soil cement under ambient with sulfate conditions. Rock and Soil Mechanics, Vol. 29, 2008, p. 659-662.

[9] Bai X. H., Zhao Y. Q., Han P. J., et al. Experimental study on mechanical property of cemented soil under environmental contaminations. Chinese Journal of Geotechnical Engineering, Vol. 29, Issue 8, 2007, p. 1260-1263. 
[10] Liu J. Z., Weng X. Z., Zhang J., et al. Research on fiber grid-cement soil base performance of airstrip. Journal of Building Materials, Vol. 17, Issue 6, 2014, p. 1043-1048.

[11] Hong L., Zhou Z. L., Yin T. B., et al. Energy consumption in rock fragmentation at intermediate strain rate. Journal of Central South University, Vol. 16, Issue 4, 2009, p. 677-682.

[12] Cao L. L., Pu H., Li M., et al. Experimental research on the dynamic tensile fracture and the energy absorption characteristics of coal-serial sandstone. Journal of China Coal Society, Vol. 42, Issue 2, 2017, p. 492-499.

[13] Ferro G., Carpinteri A. Effect of specimen size on the dissipated energy density in compression. Journal of Applied Mechanics, Vol. 75, Issue 4, 2008, p. 699-703.

[14] Shi J. S., Xu J. Y., Ren W. B., et al. Research on energy dissipation and fractal characteristics of concrete after exposure to elevated temperatures under impact loading. Acta Armamentarii, Vol. 35, Issue 5, 2014, p. 703-710.

[15] Zhang B. Y., Wang W., Wu G. H. Dynamic-compression mechanical properties and energy-absorption capability of fly-ash cenospheres-reinforced 1199Al-matrix composite foam. Explosion and Shock Waves, Vol. 32, Issue 1, 2014, p. 28-34.

[16] Luo X., Xu J. Y., Bai E. L., et al. Study on the effect of basalt fiber on the energy absorption characteristics of porous material. Construction and Building Materials, Vol. 68, 2014, p. 384-390.

[17] Daryadel S. S., Ray C., Pandya T., et al. Energy absorption of pultruded hybrid glassgraphite epoxy composites under high strain-rate SHPB compression loading. Materials Sciences and Applications, Vol. 6, Issue 6, 2015, p. 511-518.

[18] Xie W., Du H., Li S. Comparative study of energy absorption performance for open-cell aluminum and polyurethane foam aluminum. Journal of Shenyang Jianzhu University, Vol. 27, Issue 2, 2011, p. 307-311.

[19] Daryadel S. S., Mantena P. R., Kim K., et al. Dynamic response of glass under low-velocity impact and high strain-rate SHPB compression loading. Journal of Non-Crystalline Solids, Vol. 432, Issue 15, 2016, p. 432-439.

[20] Li M., Mao X. B., Li A. H., et al. Effect of specimen size on energy dissipation characteristics of red sandstone under high strain rate. International Journal of Mining Science and Technology, Vol. 24, Issue 2, 2014, p. 151-156.

[21] Ping Q., Ma Q. Y., Yuan P. Energy dissipation analysis of stone specimens in SHPB tensile test. Journal of Mining and Safety Engineering, Vol. 30, Issue 3, 2013, p. 401-407.

[22] Yu S. S., Lu Y. B., Zhu W. C., et al. Analysis on relationship between degree of damage and energy dissipation of granite in SHPB test. Journal of Northeastern University (Natural Science), Vol. 36, Issue 12, 2015, p. 1733-1737.

[23] Xu J. Y., Lu X. C., Zhang J., et al. Research on dynamic mechanical performance of amphibolite under cyclical impact loading at different confining pressures. Journal of Vibration and Shock, Vol. 29, Issue 8, 2010, p. 60-63.

[24] Zhang Y., Xu J., Yang H. W., et al. Effect of confining pressure on evolution law of hysteresis loop of sandstone under cyclic loading. Chinese Journal of Rock Mechanics and Engineering, Vol. 33, Issue 4, 2014, p. 691-698.

[25] Yang Y. M., Ju Y., Chen J. L., et al. Cracks development features and energy mechanism of dense sandstone subjected to triaxial stress. Chinese Journal of Rock Mechanics and Engineering, Vol. 33, Issue 4, 2014, p. 691-698.

[26] Li B., Xu M. G., Liu Y. Z. Application of critical state confining pressure to rock strength criteria modification. Rock and Soil Mechanics, Vol. 37, 2016, p. 390-398.

[27] Zhang T., Liu S. Y., Cai G. J. Experiment on shear behaviour of silt treated with lignin at critical state. China Journal of Highway and Transport, Vol. 29, 2016, p. 20-28.

[28] Jin J. F., Li X. B., Yin Z. Q., et al. Effect of compression and confining pressure on energy dissipation of sandstone under cyclic impact loads. Rock and Soil Mechanics, Vol. 34, Issue 11, 2013, p. 3096-3109.

[29] Lv X. C., Xu J. Y., Ge H. H., et al. Effects of confining pressure on mechanical behavious of sandstone under dynamic impact loads. Chinese Journal of Rock Mechanics and Engineering, Vol. 29, Issue 1, 2010, p. 193-201.

[30] Liu E., He S. Effects of cyclic dynamic loading on the mechanical properties of intact rock samples under confining pressure conditions. Engineering Geology, Vol. 125, Issue 27, 2012, p. 81-91.

[31] Zhang Z., Gao F. Confining pressure effect on rock energy. Chinese Journal of Rock Mechanics and Engineering, Vol. 34, Issue 1, 2015, p. 1-11. 
[32] Yi F., Zhu Z., Zu F., et al. Strain rate effects on the compressive property and the energy-absorbing capacity of aluminum alloy foams. Materials Characterization, Vol. 47, Issue 5, 2001, p. 417-422.

[33] Xie H. P., Peng R. D., Ju Y., et al. On energy analysis of rock failure. Chinese Journal of Rock Mechanics and Engineering, Vol. 24, 2005, p. 2603-2608.

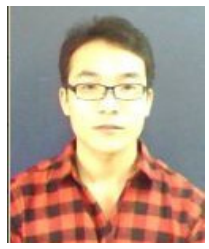

Chang-hui Gao received Undergraduate degree in civil engineering from Anhui Polytechnic University, Wuhu, P. R. China, in 2015. Now he is studying for a Master degree in Anhui University of Science and Technology, Huainan, P. R. China. His current research interests include dynamic mechanical property of cement-soil.

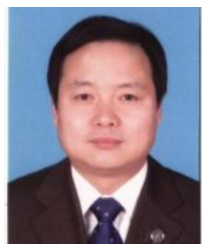

Qin-yong Ma received $\mathrm{Ph} . \mathrm{D}$. degree in civil engineering from University of Science and Technology Beijing, Beijing, P. R. China, in 2005. Now he works at Anhui University of Science and Technology. His current research interests include mechanical property of materials, control blasting technology and rapid excavation of deep roadway in coal mine. 